\title{
Dimensionless analytical solutions for dam-breach erosion
}

\section{P. Singh \& C. A. Quiroga}

To cite this article: V. P. Singh \& C. A. Quiroga (1988) Dimensionless analytical solutions for dambreach erosion, Journal of Hydraulic Research, 26:2, 179-197, DOI: 10.1080/00221688809499224

To link to this article: http://dx.doi.org/10.1080/00221688809499224

\section{Published online: 19 Jan 2010.}

Submit your article to this journal ¿

凹 Article views: 72

Q View related articles $\square$

Citing articles: 4 View citing articles 4 


\title{
Dimensionless analytical solutions for dam-breach erosion
}

\section{Solutions analytiques adimensionnelles pour l'érosion d'une breche dans un barrage}

\author{
V. P. SINGH \\ Dept. of Civil Engineering, Louisiana State University, \\ Baton Rouge, LA 70803-6405, U.S.A.
}

\author{
C. A. QUIROGA \\ Dept. of Civil Engineering, Louisiana State University, \\ Baton Rouge, LA 70803-6405, U.S.A.
}

\begin{abstract}
SUMMARY
The earthen dam breach erosion is analyzed using dimensionless analytical solutions, with rectangular and triangular representations for the breach section. Data for the historical failures of South Fork and Teton Dams are used to test these solutions. A comparison with the BEED model shows usefulness of these solutions.
\end{abstract}

\section{RÉSUMÉ}

L'érosion d'une brèche de section rectangulaire ou triangulaire dans un barrage en terre est analysée à l'aide de solutions analytiques adimensionnelles. Les données recueillies lors de la rupture des barrages de South Fork et Teton sont utilisées pour tester ces solutions. Une comparaison avec le modèle BEED montre l'utilité de ces solutions.

\section{Introduction}

Experience with physically based dam-break models such as the BEED (breach erosion of earthfill dams) model (Singh and Scarlatos, 1985, Quiroga and Singh, 1987) [7] in simulating dambreach erosion has shown that utilization of sediment transport theories such as EinsteinBrown's or Bagnold's (Simons and Senturk, 1977) [5] involves making assumptions beyond original ranges stipulated in them. These extrapolations have not yet been tested experimentally, partly for lack of data. Therefore, their utility is somewhat restricted. It may then be appropriate to define rate of erosion in terms of a single overall factor, and thus simplify the mathematical treatment of the problem so that analytical solutions become tractable.

This approach has received little attention in the past. Lou (1981) [2] defined an erodibility index in terms of the kinetic energy of water, but did not include analytical solutions. Singh and Scarlatos (1985) [7] derived analytical solutions for dam-breach erosion, assuming rectangular, triangular and trapezoidal breach sections, but did not test these solutions using historical data. This paper is an extension of the work by Singh and Scarlatos (1985) [7]. Dimensionless solutions are derived to analyze dam-breach erosion for rectangular and triangular breach sections, and tested using two historical cases. A short comparison is made with the BEED model.

Revision received August 17, 1987. Open for discussion till September 30, 1988. 


\section{General formulation}

\section{Governing equations}

Referring to the idealized breach section of Fig. 1, and neglecting the effect of any discharge into the reservoir, as well as spillway and outlet discharges, the continuity equation can be expressed as

$$
A_{\mathrm{s}} \frac{\mathrm{d} h}{\mathrm{~d} t}=-u A_{\mathrm{w}}
$$

where $A_{\mathrm{s}}$ is reservoir surface area $\left(\mathrm{m}^{2}\right), h$ is reservoir water suface elevation $(\mathrm{m}), A_{\mathrm{w}}$ is wetted area of the breach section $\left(\mathrm{m}^{2}\right)$, and $u$ is water velocity at the breach section $(\mathrm{m} / \mathrm{s})$. For simplicity, $u$ can be defined as follows:

$$
u=C_{\mathrm{u}}(h-z)^{\mathrm{a}}
$$

where $C_{\mathrm{u}}$ is a proper coefficient, and $a$ is an exponent. Usually, the exponent $a$ is assumed to be 0.5. Under this assumption, $C_{\mathrm{u}}$ ranges from 1.2 to $1.7 \sqrt{\mathrm{m}} / \mathrm{s}$ (Singh and Quiroga, 1986) [6]. Breach erosion depends on water velocity and geotechnical properties of the dam material. In a simplified model, rate of erosion can be defined as

$$
\frac{\mathrm{d} z}{\mathrm{~d} t}=-E_{\mathrm{f}} u^{\mathrm{n}}
$$

where $z$ is breach bottom elevation $(\mathrm{m}), E_{\mathrm{f}}$ is an erodibility factor, and $n$ is a proper exponent. Units of $E_{\mathrm{f}}$ depend on the value of $n$.

In order to obtain unique solutions, initial conditions are specified as

$$
h(0)=H_{0}, \quad z(0)=Z_{0}
$$

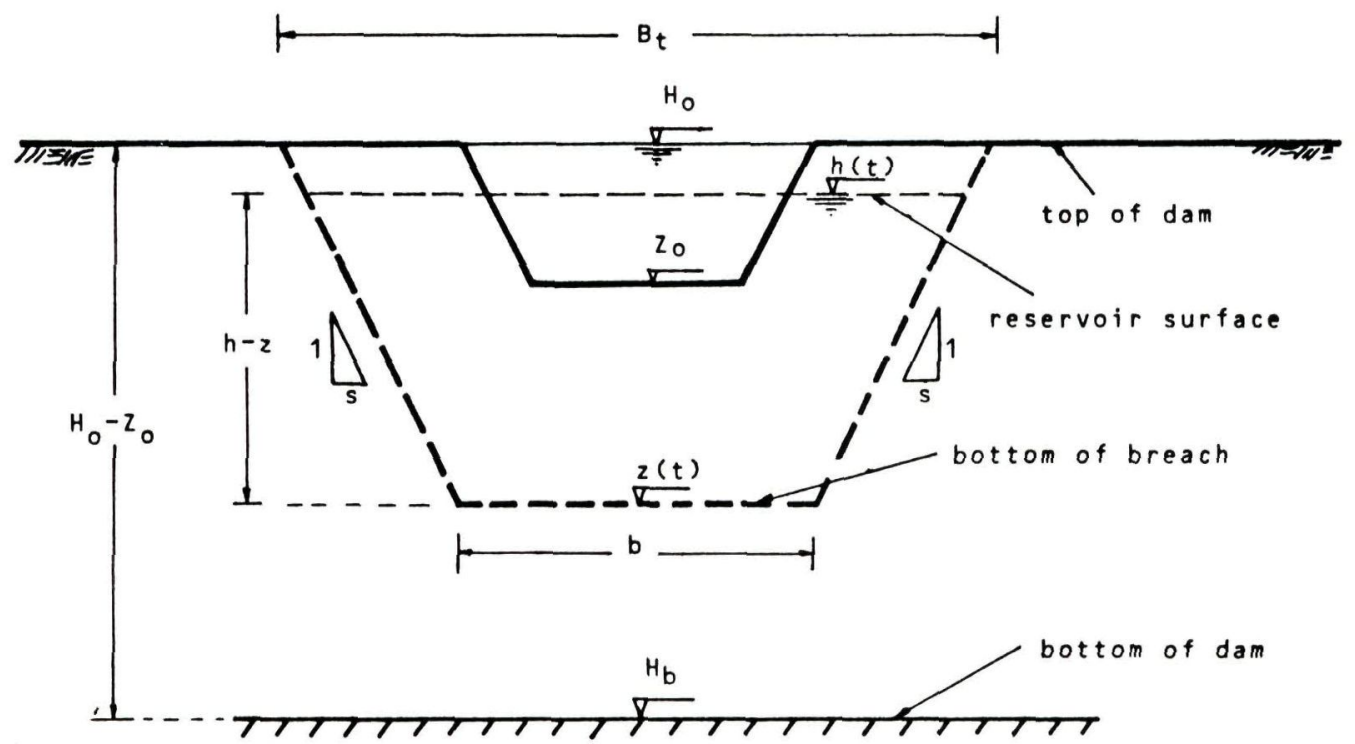

Fig. 1. Idealized breach section.

Section schématique de la brèche. 
where $H_{0}$ is initial reservoir water surface elevation $(\mathrm{m})$, and $Z_{0}$ is initial breach bottom elevation $(\mathrm{m})$.

\section{Dimensionless formulation}

Nondimensionalized equations lead to reduction of parameters and increased understanding of the problem. To this end, it is convenient to define the following normalizing quantities:

$$
h^{\prime}=\frac{h-H_{\mathrm{b}}}{H_{0}-H_{\mathrm{b}}}
$$

where $h^{\prime}$ is a dimensionless quantity representing reservoir water surface elevation, and $\mathrm{H}_{\mathrm{b}}$ is dam bottom elevation (m). At $h=H_{0}, h^{\prime}=1$. At $h=H_{\mathrm{b}}, h^{\prime}=0$;

$$
z^{\prime}=\frac{z-H_{\mathrm{b}}}{Z_{0}-H_{\mathrm{b}}}
$$

where $z^{\prime}$ is a dimensionless quantity representing breach bottom elevation. At $z=Z_{0}, z^{\prime}=1$. At $z=H_{\mathrm{b}}, z^{\prime}=0$;

$$
t^{\prime}=\frac{t}{T_{\mathrm{f}}}
$$

where $t^{\prime}$ is a dimensionless quantity representing time, and $T_{\mathrm{f}}$ is breach formulation time (s). At $t=0, t^{\prime}=0$. At $t=T_{\mathrm{f}}, t^{\prime}=1$.

The reference terms $H_{0}, Z_{0}$ and $H_{\mathrm{b}}$ are known from dam geometry data. However, in order to determine $T_{\mathrm{f}}$, the mathematical solution of the problem must be obtained first. As shown later, it is possible to derive expressions for $T_{\mathrm{f}}$ based entirely on parameters that are provided beforehand. Therefore, the normalization is complete.

\section{Dimensionless solutions}

First, a general methodology to obtain dimensionless analytical solutions for dam-breach erosion is developed. Then, particular solutions are attempted for rectangular and triangular breach sections. Analytical solutions were not wieldly for the trapezoidal section. Throughout the analysis, $A_{\mathrm{S}}$ is assumed to remain constant, and the exponent $a$ is assumed to be 0.5 .

\section{Rectangular section}

In this case,

$$
A_{\mathrm{w}}=b(h-z)
$$

Inserting equations (8) and (2) in equation (1),

$$
\frac{\mathrm{d} h}{\mathrm{~d} t}=-\frac{b C_{\mathrm{u}}}{A_{\mathrm{s}}}(h-z)^{1.5}
$$

Replacing $u$ from equation (2) into equation (3),

$$
\frac{\mathrm{d} z}{\mathrm{~d} t}=-E_{\mathrm{f}} C_{\mathrm{u}}^{\mathrm{n}}(h-z)^{0.5 \mathrm{n}}
$$


In order to generalize the solution procedure, it is convenient to derive, first, an expression that expresses $h$ in terms of $z$, and then, another one that expresses $h$ and $z$ in terms of $t$. Dividing equation (9) by equation (10) leads to

$$
\frac{\mathrm{d} h}{\mathrm{~d} z}=\frac{b}{A_{\mathrm{s}} E_{\mathrm{f}} C_{\mathrm{u}}^{\mathrm{n}-1}}(h-z)^{(3-\mathrm{n}) / 2}
$$

Replacing $h$ and $z$ from equations (5) and (6) into equation (11),

$$
\left(\frac{H_{0}-H_{\mathrm{b}}}{Z_{0}-H_{\mathrm{b}}}\right)\left(\frac{\mathrm{d} h^{\prime}}{\mathrm{d} z^{\prime}}\right)=\frac{b}{A_{\mathrm{s}} E_{\mathrm{f}} C_{\mathrm{u}}^{\mathrm{n}-1}}\left[\left(H_{0}-H_{\mathrm{b}}\right) h^{\prime}-\left(Z_{0}-H_{\mathrm{b}}\right) z^{\prime}\right]^{(3-\mathrm{n}) / 2}
$$

By defining

$$
H=\left(\frac{b}{A_{\mathrm{s}} E_{\mathrm{f}} C_{\mathrm{u}}^{\mathrm{n}-1}}\right)^{2 /(3-\mathrm{n})}\left(H_{0}-H_{\mathrm{b}}\right)
$$

and

$$
Z=\left(\frac{b}{A_{\mathrm{s}} E_{\mathrm{f}} C_{\mathrm{u}}^{\mathrm{n}-1}}\right)^{2 /(3-\mathrm{n})}\left(Z_{0}-H_{\mathrm{b}}\right)
$$

where $H$ and $Z$ are two dimensionless parameters, equation (12) can be simplified as follows:

$$
\frac{\mathrm{d} h^{\prime}}{\mathrm{d} z^{\prime}}=\frac{Z}{H}\left(H h^{\prime}-Z z^{\prime}\right)^{(3-\mathrm{n}) / 2}
$$

But

$$
\frac{\mathrm{d}\left(H h^{\prime}-Z z^{\prime}\right)}{\mathrm{d} z^{\prime}}=H \frac{\mathrm{d} h^{\prime}}{\mathrm{d} z^{\prime}}-Z
$$

or

$$
\frac{\mathrm{d} h^{\prime}}{\mathrm{d} z^{\prime}}=\frac{1}{H}\left[\frac{\mathrm{d}\left(H h^{\prime}-Z z^{\prime}\right)}{\mathrm{d} z^{\prime}}+Z\right]
$$

Then, substituting equation (16) into equation (15),

$$
\int \frac{\mathrm{d}\left(H h^{\prime}-Z z^{\prime}\right)}{\left(H h^{\prime}-Z z^{\prime}\right)^{(3-\mathrm{n}) / 2}-1}=Z z^{\prime}=K
$$

Equation (17) is the general dimensionless equation that relates reservoir water surface elevation to breach bottom elevation for a rectangular breach section.

At this point, it may be noted that equation (17) has been cast in terms of two parameters: $H$ and $Z$. These parameters are not only dimensionless but also entirely based on information that is given beforehand. Therefore, equation (17) is general.

Replacing $h$ and $t$ from equations (5) and (7) into equation (9),

$$
\frac{\mathrm{d} h^{\prime}}{\mathrm{d} t^{\prime}}=-\frac{T}{H}\left(H h^{\prime}-Z z^{\prime}\right)^{1.5}
$$


where

$$
T=\left(\frac{b}{A_{\mathrm{s}} E_{\mathrm{f}} C_{\mathrm{u}}^{\mathrm{n}-1}}\right)^{(2-\mathrm{n}) /(3-\mathrm{n})} E_{\mathrm{f}} C_{\mathrm{u}}^{\mathrm{n}} T_{\mathrm{f}}
$$

is a dimensionless parameter. Dividing equation (18) by equation (15),

$$
\frac{\mathrm{d} z^{\prime}}{\mathrm{d} t^{\prime}}=-\frac{T}{Z}\left(H h^{\prime}-Z z^{\prime}\right)^{0.5 n}
$$

Subtracting equation (20) from equation (18) leads finally to

$$
\int \frac{\mathrm{d}\left(H h^{\prime}-Z z^{\prime}\right)}{\left(H h^{\prime}-Z z^{\prime}\right)^{1.5}-\left(H h^{\prime}-Z z^{\prime}\right)^{0.5 n}}=-T t^{\prime}+K
$$

Equation (21) is the general dimensionless equation that relates reservoir water surface elevation and breach bottom elevation to time for a rectangular breach section.

From equation (19), it may seen that, in order to apply equation (21), it would be necessary to know $T_{\mathrm{f}}$, which is supposed to be one of the results from the solution. However, as shown later, it is possible to derive expressions for $T$ independently of $T_{\mathrm{f}}$ and based entirely on information given beforehand.

This study is limited to determining dimensionless analytical solutions for two particular cases: a. $n=1$, and b. $n=2$. The methodology, however, can easily be extended to higher values of $n$, as shown below.

Linear case: $n=1$

In this case, equation (17) becomes

$$
\int \frac{\mathrm{d}\left(H h^{\prime}-Z z^{\prime}\right)}{\left(H h^{\prime}-Z z^{\prime}\right)-1}=Z z^{\prime}+K
$$

After integrating,

$$
\ln \left[\left(H h^{\prime}-Z z^{\prime}\right)-1\right]=Z z^{\prime}+K
$$

From initial conditions, for $z^{\prime}=1, h^{\prime}=1$. This means that

$$
K=\ln (H-Z-1)-Z
$$

Finally,

$$
H h^{\prime}-Z z^{\prime}=1+(H-Z-1) \exp \left[Z\left(z^{\prime}-1\right)\right]
$$

Equation (23) prescribes $h^{\prime}$ as a function of $z^{\prime}$ and breach characteristics. In order to define $h^{\prime}$ and $z^{\prime}$ in terms of $t^{\prime}$, equation (21) becomes

$$
\int \frac{\mathrm{d}\left(H h^{\prime}-Z z^{\prime}\right)}{\left(H h^{\prime}-Z z^{\prime}\right)^{1.5}-\left(H h^{\prime}-Z z^{\prime}\right)^{0.5}}=-T t^{\prime}+K
$$

Defining

$$
H h^{\prime}-Z z^{\prime}=p^{2}
$$


then,

$$
2 \int \frac{\mathrm{d} p}{p^{2}-1}=-T t^{\prime}+K
$$

Referring to page 65 of Spiegel (1968) [8],

$$
\ln \frac{p-1}{P+1}=-T t^{\prime}+K
$$

Inserting the transformation back,

$$
\ln \frac{\sqrt{H h^{\prime}-Z z^{\prime}}-1}{\sqrt{H h^{\prime}-Z z^{\prime}}+1}=-T t^{\prime}+K
$$

From initial conditions, at $t^{\prime}=0, h^{\prime}=1$ and $z^{\prime}=1$.

This means that

$$
K=\ln \frac{\sqrt{H-Z}-1}{\sqrt{H-Z}+1}
$$

Therefore, the solution of equation (24) is

$$
\ln \frac{\sqrt{H h^{\prime}-Z z^{\prime}}-1}{\sqrt{H h^{\prime}-Z z^{\prime}}+1}-\ln \frac{\sqrt{H-Z}-1}{\sqrt{H-Z}+1}=-T t^{\prime}
$$

Equation (25) prescribes $h^{\prime}$ and $z^{\prime}$ in terms of $t^{\prime}$. Only Tremains to be determined. From equations (5), (6) and (7), for $t^{\prime}=1, z^{\prime}=0$, but $h^{\prime}=h^{\prime \prime}>0$, where $h^{\prime \prime}$ can be obtained from equation (23) as follows:

$$
H h^{\prime}=1+(H-Z-1) \exp (-Z)
$$

Therefore, from equation (25),

$$
T=\ln \frac{\sqrt{H-Z}-1}{\sqrt{H-Z}+1}-\ln \frac{\sqrt{1+(H-Z-1) \exp (-Z)}-1}{\sqrt{1+(H-Z-1) \exp (-Z)}+1}
$$

It may be noted from equation (27) that $T$ is a function of $H$ and $Z$, that is, parameters that are known in advance.

Nonlinear case: $n=2$

In this case, equation (17) becomes

$$
\int \frac{\mathrm{d}\left(H h^{\prime}-Z z^{\prime}\right)}{\left(H h^{\prime}-Z z^{\prime}\right)^{0.5}-1}=Z z^{\prime}+K
$$

As before, by defining

$$
H h^{\prime}-Z z^{\prime}=p^{2}
$$

the solution of equation (28) can be shown to be

$$
z^{\prime}=1+\frac{2}{Z}\left[\sqrt{H h^{\prime}-Z z^{\prime}}-\sqrt{H-Z}+\ln \frac{1-\sqrt{H h^{\prime}-Z z^{\prime}}}{1-\sqrt{H-Z}}\right]
$$


As for the linear case, once $h^{\prime}$ is defined in terms of $z^{\prime}$, the second step is to find an expression for $\left(h^{\prime}-z^{\prime}\right)$ in terms of $t^{\prime}$. To this end, equation (21) becomes

$$
\int \frac{\mathrm{d}\left(H h^{\prime}-Z z^{\prime}\right)}{\left(H h^{\prime}-Z z^{\prime}\right)^{1.5}-\left(H h^{\prime}-Z z^{\prime}\right)}=-T t^{\prime}+K
$$

As before, by defining

$$
H h^{\prime}-Z z^{\prime}=p^{2}
$$

it can be shown that the solution of equation $(30)$ is

$$
2 \ln \frac{\sqrt{H h^{\prime}-Z z^{\prime}}}{\sqrt{H h^{\prime}-Z z^{\prime}}-1}-2 \ln \frac{\sqrt{H-Z}}{\sqrt{H-Z}-1}=T t^{\prime}
$$

Equation (31) prescribes $h^{\prime}$ and $z^{\prime}$ in terms of $t^{\prime}$. As before, only $T$ remains to be determined. At $t^{\prime}=1, z^{\prime}=0$ and $h^{\prime}=h^{\prime \prime}$, where $h^{\prime \prime}$ can be obtained from equation (29) by some iterative procedure. It turns out that $h^{\prime \prime}$ is a function of only $H$ and $Z$. Finally, from equation (31),

$$
T=2 \ln \frac{1-1 / \sqrt{H-Z}}{1-1 / \sqrt{H h^{\prime \prime}}}
$$

As before, $T$ is entirely dependent on $H$ and $Z$.

\section{Triangular section}

In this case,

$$
A_{\mathrm{w}}=s(h-z)^{2}
$$

Following the same procedure as the one utilized for rectangular section,

$$
\begin{aligned}
\frac{\mathrm{d} h^{\prime}}{\mathrm{d} z^{\prime}} & =\frac{Z}{H}\left(H h^{\prime}-Z z^{\prime}\right)^{(5-\mathrm{n}) / 2} \\
\frac{\mathrm{d} h^{\prime}}{\mathrm{d} t^{\prime}} & =-\frac{T}{H}\left(H h^{\prime}-Z z^{\prime}\right)^{2.5} \\
\frac{\mathrm{d} z^{\prime}}{\mathrm{d} t^{\prime}} & =-\frac{T}{Z}\left(H h^{\prime}-Z z^{\prime}\right)^{0.5 \mathrm{n}}
\end{aligned}
$$

where

$$
\begin{aligned}
H & =\left(\frac{s}{A_{\mathrm{s}} E_{\mathrm{f}} C_{\mathrm{u}}^{\mathrm{n}-1}}\right)^{2 /(5-\mathrm{n})}\left(H_{0}-H_{\mathrm{b}}\right) \\
Z & =\left(\frac{s}{A_{\mathrm{s}} E_{\mathrm{f}} C_{\mathrm{u}}^{\mathrm{n}-1}}\right)^{2 /(5-\mathrm{n})}\left(Z_{0}-H_{\mathrm{b}}\right) \\
T & =\left(\frac{s}{A_{\mathrm{s}} E_{\mathrm{f}} C_{\mathrm{u}}^{\mathrm{n}-1}}\right)^{(2-\mathrm{n}) /(5-\mathrm{n})} E_{\mathrm{f}} C_{\mathrm{u}}^{\mathrm{n}} T_{\mathrm{f}}
\end{aligned}
$$

Substituting equation (16) into equation (34),

$$
\int \frac{\mathrm{d}\left(H h^{\prime}-Z z^{\prime}\right)}{\left(H h^{\prime}-Z z^{\prime}\right)^{(5-\mathrm{n}) / 2}-1}=Z z^{\prime}+K
$$


Equation (40) is the general dimensionless equation that relates reservoir water surface elevation to breach bottom elevation for a triangular breach section. After subtracting equation (36) from equation (35),

$$
\int \frac{\mathrm{d}\left(H h^{\prime}-Z z^{\prime}\right)}{\left(H h^{\prime}-Z z^{\prime}\right)^{2.5}-\left(H h^{\prime}-Z z^{\prime}\right)^{0.5 n}}=-T t^{\prime}+K
$$

Equation (41) is the general dimensionless equation that relates the variation of water surface elevation and breach bottom elevation to time for a triangular breach section. As for rectangular section, two cases are considered: a. $n=1$, and b. $n=2$.

Linear case: $n=1$

In this case, equation (40) becomes

$$
\int \frac{\mathrm{d}\left(H h^{\prime}-Z z^{\prime}\right)}{\left(H h^{\prime}-Z z^{\prime}\right)^{2}-1}=Z z^{\prime}+K
$$

Using the same transformation as before, it can be shown that the solution of equation (42) is

$$
z^{\prime}=1+\frac{1}{2 Z}\left[\ln \frac{H h^{\prime}-Z z^{\prime}-1}{H h^{\prime}-Z z^{\prime}+1}-\ln \frac{H-Z-1}{H-Z+1}\right]
$$

Also, equation (41) becomes

$$
\int \frac{\mathrm{d}\left(H h^{\prime}-Z z^{\prime}\right)}{\left(H h^{\prime}-Z z^{\prime}\right)^{2.5}-\left(H h^{\prime}-Z z^{\prime}\right)^{0.5}}=-T t^{\prime}+K
$$

Similarly, it can be shown that the solution of equation (44) can be expressed as

$$
\ln \frac{1-\sqrt{H h^{\prime}-Z z^{\prime}}}{1+\sqrt{H h^{\prime}-Z z^{\prime}}}-2 \arctan \sqrt{H h^{\prime}-Z z^{\prime}}=\ln \frac{1-\sqrt{H-Z}}{1+\sqrt{H-Z}}-2 \arctan \sqrt{H-Z}-2 T t^{\prime}
$$

At $t^{\prime}=1, z^{\prime}=0$ and $h^{\prime}=h^{\prime \prime}$, where $h^{\prime \prime}$ can be obtained from equation (43) as follows:

$$
H h^{\prime \prime}=\frac{\frac{1+H-Z}{1-H+Z} \exp (2)-1}{\frac{1+H-Z}{1-H+Z} \exp (2)+1}
$$

Once $h^{\prime \prime}$ is known, an expression for $T$ can be derived from equation (45) as follows:

$$
T=\frac{1}{2}\left[\ln \frac{1-\sqrt{H-Z}}{1+\sqrt{H-Z}}-2 \arctan \sqrt{H-Z}-\ln \frac{1-\sqrt{H h^{\prime \prime}}}{1+\sqrt{H h^{\prime \prime}}}+2 \arctan \sqrt{H h^{\prime \prime}}\right]
$$

Nonlinear case: $n=2$

In this case, equation (40) becomes

$$
\int \frac{\mathrm{d}\left(H h^{\prime}-Z z^{\prime}\right)}{\left(H h^{\prime}-Z z^{\prime}\right)^{1.5}-1}=Z z^{\prime}+K
$$


As before, it can be shown that the solution for equation (48) is

$$
\begin{aligned}
z^{\prime}=1 & +\frac{1}{3 Z}\left[\ln \frac{\left(1-\sqrt{H h^{\prime}-Z z^{\prime}}\right)^{2}}{1+\sqrt{H h^{\prime}-Z z^{\prime}}+H h^{\prime}-Z z^{\prime}}+\right. \\
& +2 \sqrt{3} \arctan \frac{2 \sqrt{H h^{\prime}-Z z^{\prime}}+1}{\sqrt{3}}-\ln \frac{(1-\sqrt{H-Z})^{2}}{1+\sqrt{H-Z}+H-Z}- \\
& \left.-2 \sqrt{3} \arctan \frac{2 \sqrt{H-Z}+1}{\sqrt{3}}\right]
\end{aligned}
$$

Now equation (41) becomes

$$
\int \frac{\mathrm{d}\left(H h^{\prime}-Z z^{\prime}\right)}{\left(H h^{\prime}-Z z^{\prime}\right)^{2.5}-\left(H h^{\prime}-Z z^{\prime}\right)}=-T t^{\prime}+K
$$

The solution for equation (50) can be shown to be

$$
\frac{2}{3} \ln \frac{(H-Z)^{3 / 2}-1}{(H-Z)^{3 / 2}}-\frac{2}{3} \ln \frac{\left(H h^{\prime}-Z z^{\prime}\right)^{3 / 2}-1}{\left(H h^{\prime}-Z z^{\prime}\right)^{3 / 2}}=T t^{\prime}
$$

At $t^{\prime}=1, z^{\prime}=0$ and $h^{\prime}=h^{\prime \prime}$, where $h^{\prime \prime}$ can be obtained from equation (49) by some iterative procedure. As before, $h^{\prime \prime}$ turns out to depend only on $H$ and $Z$. The parameter $T$ can now be determined from equation (31) as follows:

$$
T=\frac{2}{3} \ln \frac{1 /(H-Z)^{3 / 2}-1}{1 /\left(H h^{\prime \prime}\right)^{3 / 2}-1}
$$

As before, $T$ is entirely based on $H$ and $Z$.

\section{Comparison with the BEED model}

The BEED model (Singh and Scarlatos, 1985 [7], Singh and Quiroga, 1987) [6] is a physically based model that considers dam-breach evolution, flood routing and sediment routing. Simulation of dam-breach evolution is based on hydrologic, geometric and geotechnic considerations. Einstein-Brown's and Bagnold's equations are utilized to compute rate of erosion in the breached section. A water routing scheme, based on a modified version of the Muskingum method to simulate flow exchange between channel and floodplains, is used to route the resulting breach hydrograph. A sediment routing scheme based on the Muskingum method, modified to simulate deposition in floodplains, and deposition and scouring in the channel is utilized to route the breach sediment graph.

The most important differences between the dimensionless analytical solutions for dam-breach erosion derived in this study and the BEED model are summarized as follows:

a. In the BEED model, $A_{\mathrm{s}}$ is assumed to be variable; in the analytical solutions, for simplicity, $A_{\mathrm{s}}$ is taken as constant.

b. In the BEED model, breach section can be triangular, rectangular or trapezoidal. In the analytical solutions, only rectangular and triangular sections are considered.

c. As opposed to the BEED model, in the analytical solutions only the breach discharges water from the reservoir.

d. With the BEED model, the entire breach hydrograph can be determined. With the analytical 


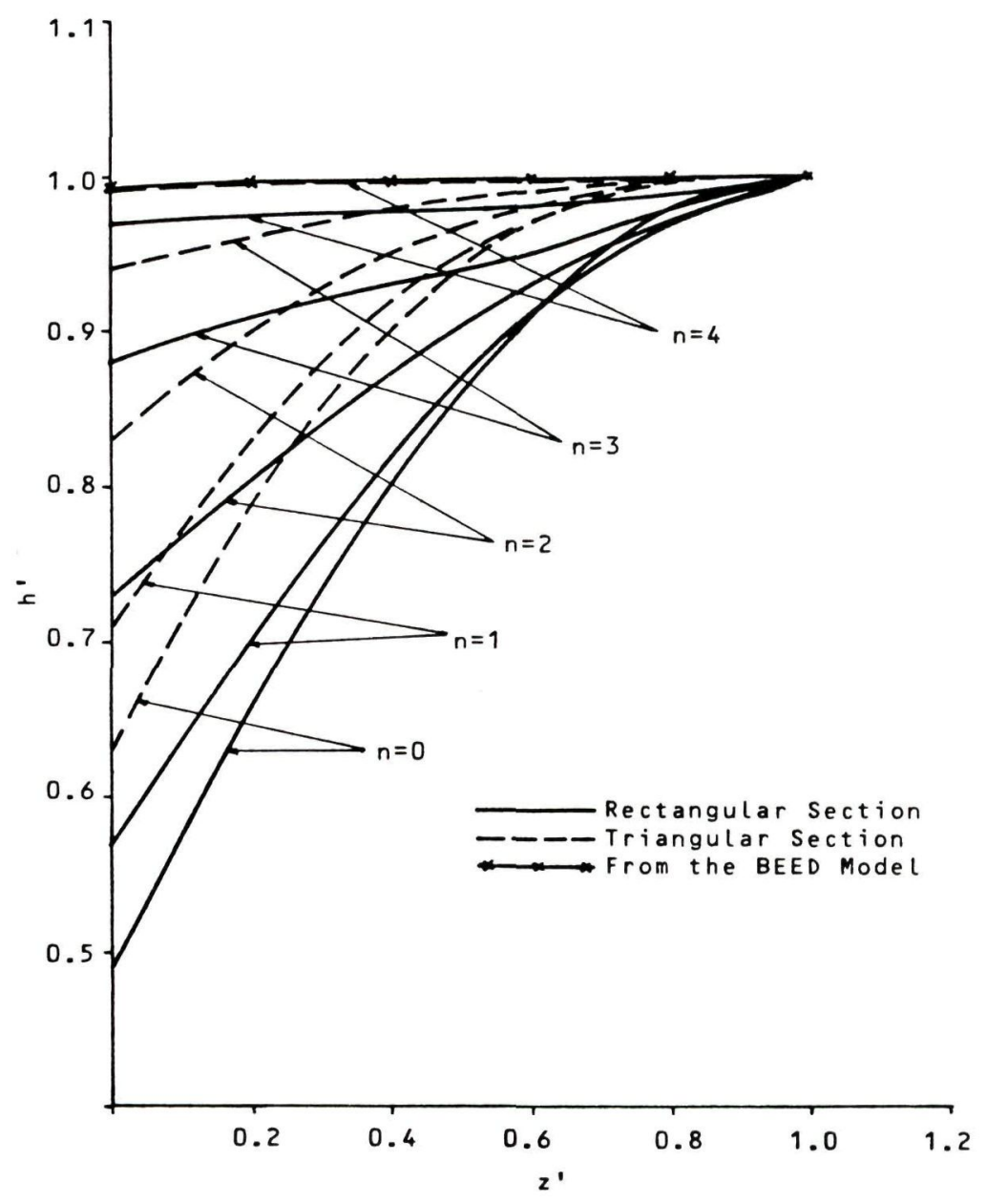

Fig. 2. Relation between $h^{\prime}$ and $z^{\prime}$ for the South Fork Dam.

Relation entre $h^{\prime}$ et $z^{\prime}$ pour le barrage de South Fork.

solutions derived in this study, only the rising part of the breach hydrograph is obtained.

e. In the BEED model, rate of erosion at the breach is determined using a sediment transport equation. In the analytical solutions, rate of erosion is computed by means of an overall erodibility factor.

From the standpoint of results, the comparison is made with respect to the influence of $n$ on the breach hydrograph. As shown later, as $n$ increases, computed values of $Q_{p}$ (peak discharge) tend to approach those given by the BEED model. Also, as shown in Figs. 2 to 7, higher $n$ values correspond to closer agreement between analytical solutions and the BEED model.

\section{Verification of the dimensionless solutions}

Dimensionless analytical solutions for dam-breach erosion were obtrained for two particular cases: $n=1$, and $n=2$. However, to get the solution for an arbitrary value of $n$, a numerical approximation scheme, similar to the one used in the BEED model, was utilized to solve 


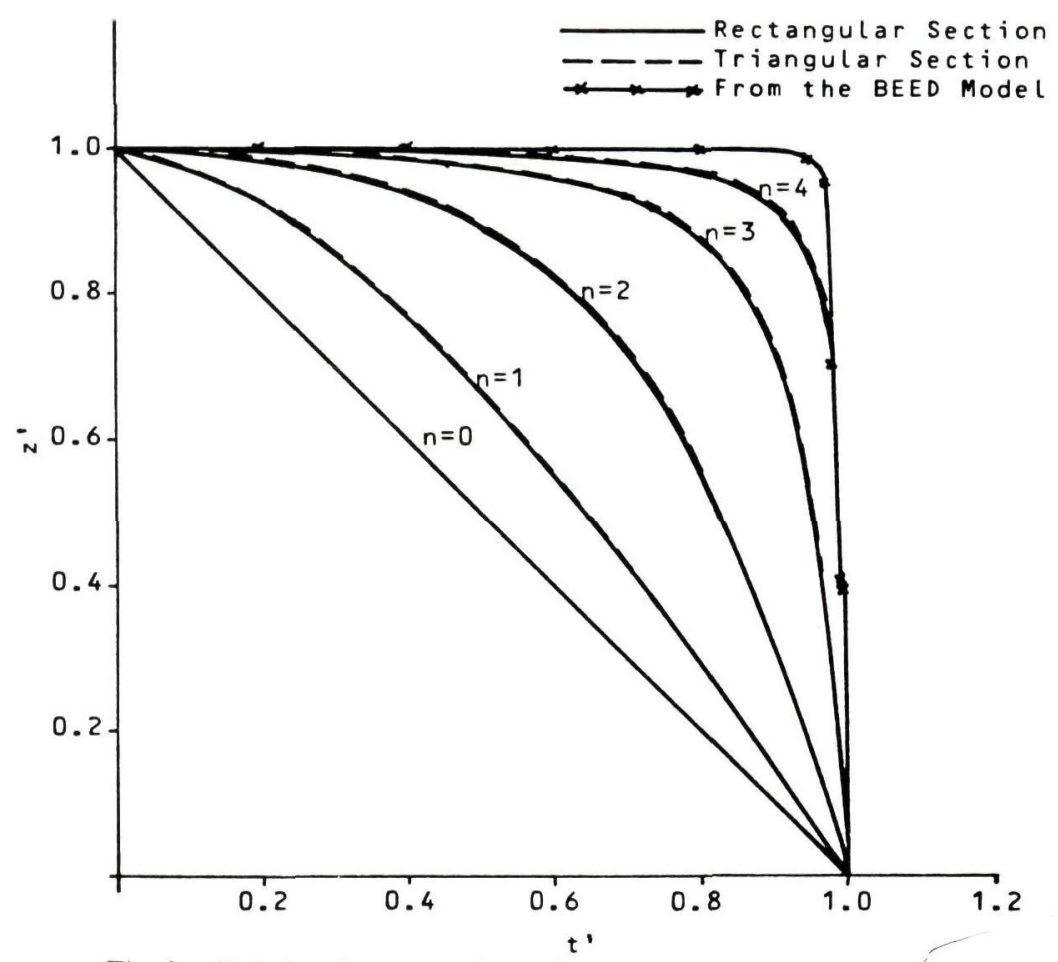

Fig. 3. Relation between $z^{\prime}$ and $t^{\prime}$ for the South Fork Dam. Relation entre $z^{\prime}$ et $t^{\prime}$ pour le barrage de South Fork.

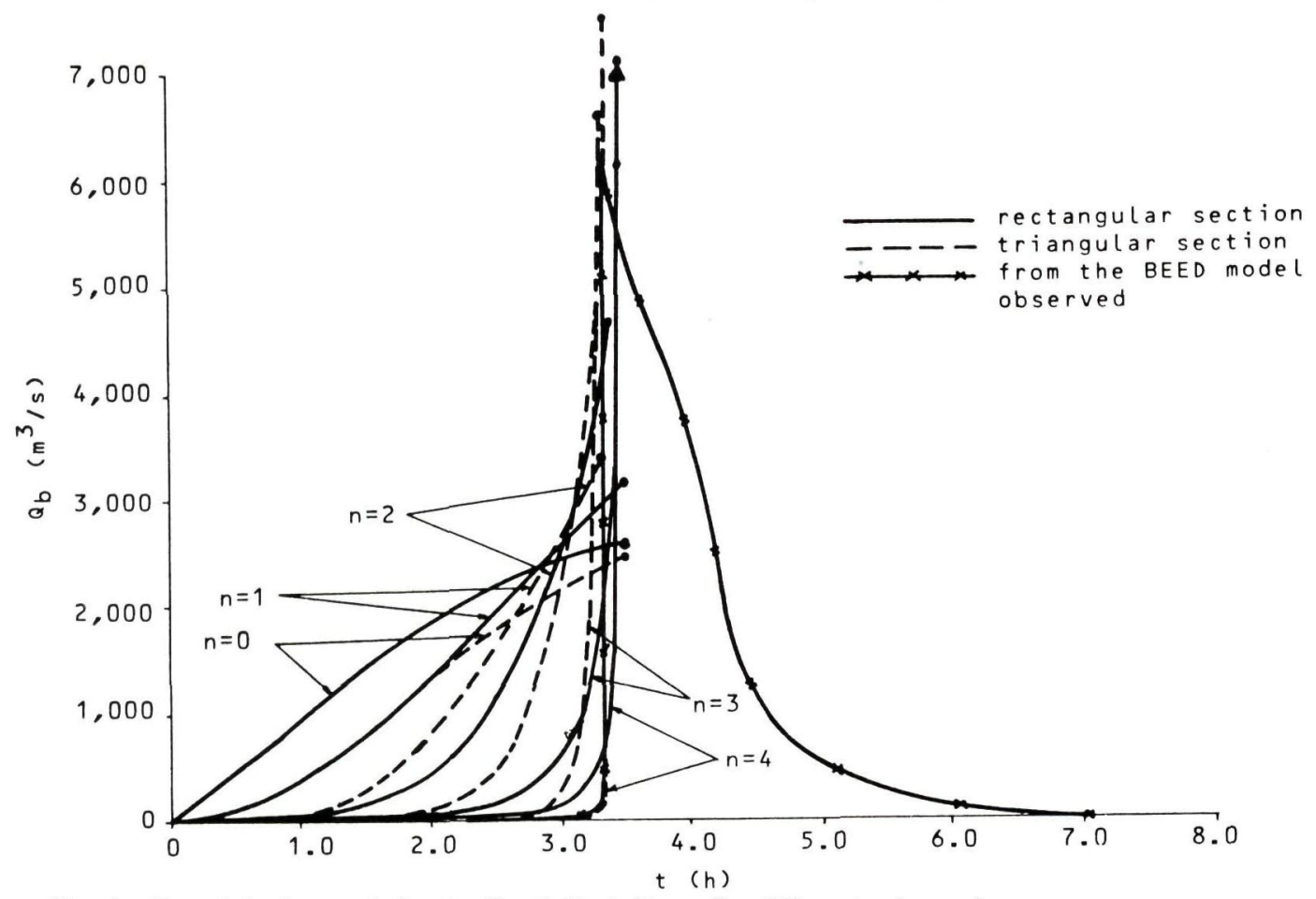

Fig. 4. Breach hydrograph for the South Fork Dam, for different values of $n$.

Evolution du débit de la brèche du barrage de South Fork, pour différentes valeurs de $n$. 


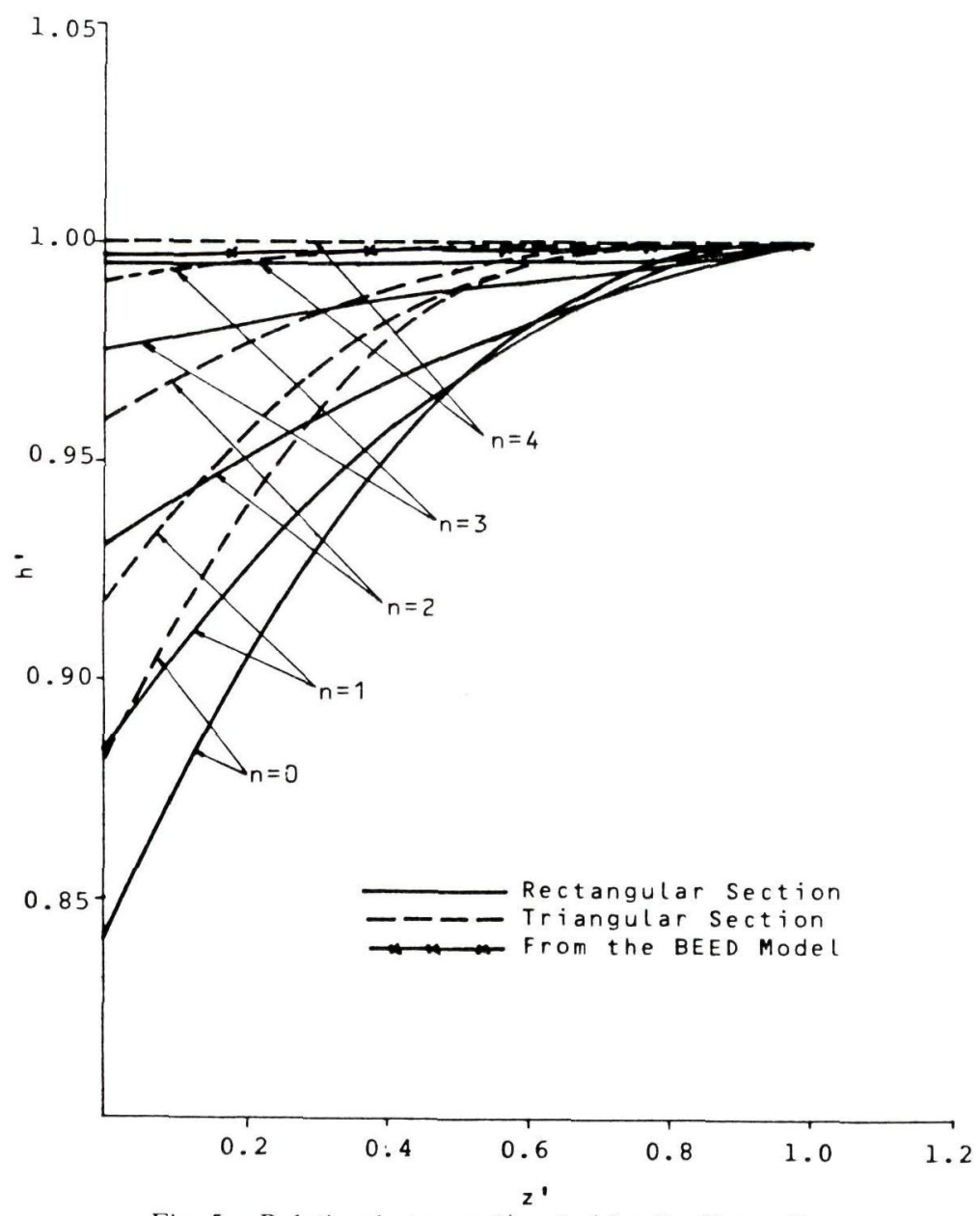

Fig. 5. Relation between $h^{\prime}$ and $z^{\prime}$ for the Teton Dam. Relation entre $h^{\prime}$ et $z^{\prime}$ pour le barrage de Teton.

equations (1) and (3). In general, these solutions contain expressions for $h^{\prime}$ and $T$, that are used to compute $Q_{\mathrm{p}}$ and $T_{\mathrm{f}}$. For a breach to develop completely, the rate of erosion at the breach must be larger than the rate of depletion of the reservoir. This means that $Q_{\mathrm{p}}$ must occur when $\left(h^{\prime}-z^{\prime}\right)$ is maximum. This normally happens at $t=T_{\mathrm{f}}$. At this moment, $h^{\prime}-z^{\prime}=h^{\prime \prime}$. Therefore, for a rectangular breach section,

$$
Q_{\mathrm{p}}=b C_{\mathrm{u}}\left[h^{\prime \prime}\left(H_{0}-H_{\mathrm{b}}\right)\right]^{1.5}
$$

Similarly, for a triangular section,

$$
Q_{\mathrm{p}}=s C_{\mathrm{u}}\left[h^{\prime \prime}\left(H_{0}-H_{\mathrm{b}}\right)\right]^{2.5}
$$

Values of $E_{\mathrm{f}}$ are assumed in such a way that breach formation times coincide with actual observations. By doing so, it is easier to establish the relation between $n$ and peak discharge. For comparison of the dimensionless analytical solutions for dam-breach erosion with the BEED model, the following historical cases are considered: South Fork Dam and Teton Dam. 


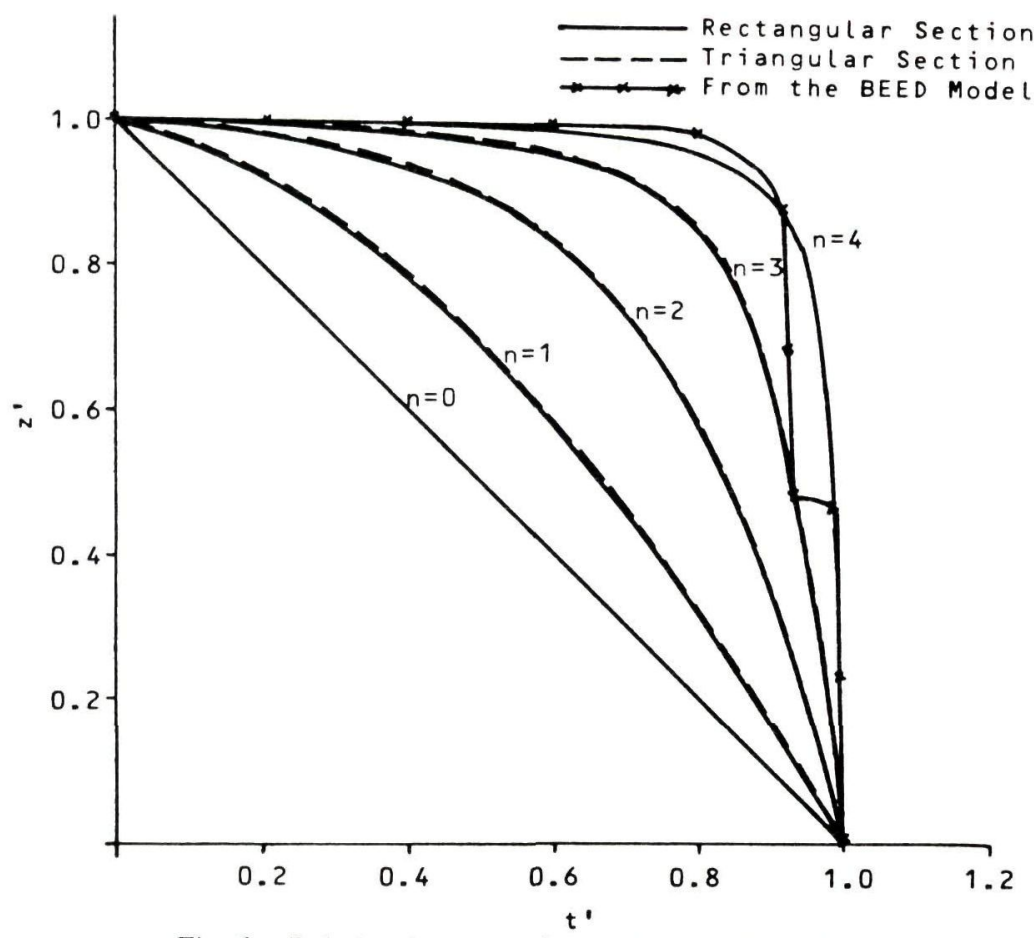

Fig. 6. Relation between $z^{\prime}$ and $t^{\prime}$ for the Teton Dam.

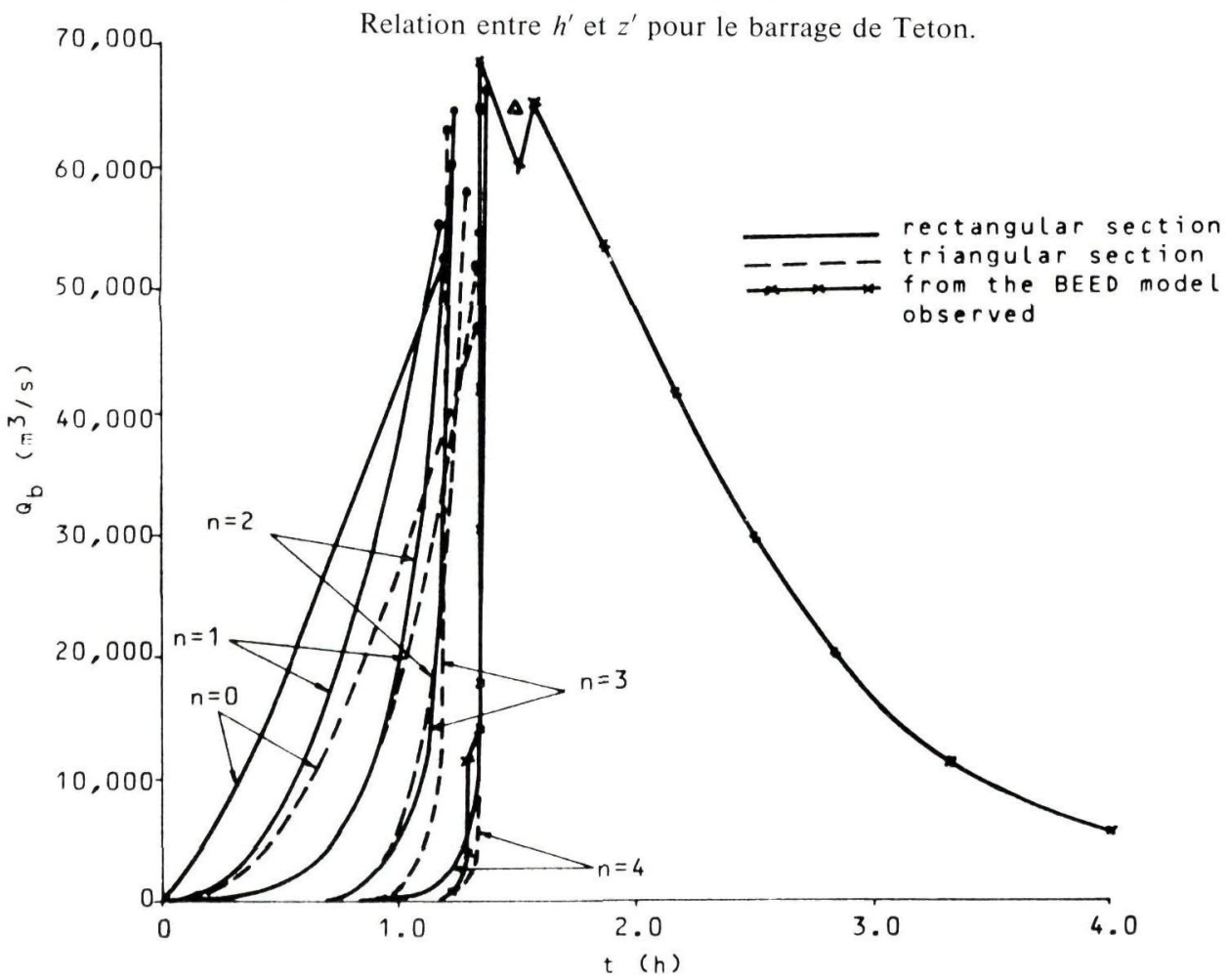

Fig. 7. Breach hydrograph for the Teton Dam, for different values of $n$.

Evolution du débit de la brèche du barrage de Teton, pour différentes valeurs de $n$. 


\section{South Fork Dam}

The South Fork Dam, located near Johnstown, Pennsylvania, failed on May 31, 1889, due to overtopping caused by extremely heavy rainfall [1]. The $23 \mathrm{~m}$ high dam was built with earth and gravel. At the time of failure, approximately $18,900,000 \mathrm{~m}^{3}$ of water with a surface area of 165 ha was contained in the reservoir. The peak discharge through the breach was estimated to be 5,600 to $8,500 \mathrm{~m}^{3} / \mathrm{s}$. It took 3.5 hours for the breach to develop completely.

For application of the dimensionless analytical solutions, the following input parameters are assumed: $H_{0}=23.0 \mathrm{~m}, Z_{0}=22.8 \mathrm{~m}, H_{\mathrm{b}}=0, A_{\mathrm{s}}=1,647,129 \mathrm{~m}^{2}$, and $C_{\mathrm{u}}=1.5 \sqrt{\mathrm{m}} / \mathrm{s}$. For the rectangular section case, $b$ is assumed to be $45 \mathrm{~m}$. For the triangular section case, $s$ is assumed to be 2.02. These input parameters and the corresponding dimensionless parameters are tabulated in Table 1.

Table 1. Input data and dimensionless parameters for application of the analytical solutions to the South Fork Dam

\begin{tabular}{|c|c|c|c|c|c|}
\hline \multirow[b]{2}{*}{ variable } & \multicolumn{5}{|c|}{ exponent $n$} \\
\hline & 0 & 1 & 2 & 3 & 4 \\
\hline \multicolumn{6}{|c|}{$\begin{array}{l}H_{0}=23.0 \mathrm{~m} \\
Z_{0}=22.8 \mathrm{~m} \\
H_{\mathrm{b}}=0.0 \mathrm{~m} \\
A_{\mathrm{s}}=1,647,129 \mathrm{~m}^{2} \\
C_{\mathrm{u}}=1.5 \sqrt{\mathrm{m}} / \mathrm{s}\end{array}$} \\
\hline \multicolumn{6}{|c|}{$\begin{array}{l}\text { rectangular section: } \\
b=45.0 \mathrm{~m}\end{array}$} \\
\hline$E_{\mathrm{f}}$ & 0.0018 & 0.0005 & 0.00019 & 0.00010 & 0.00008 \\
\hline$H$ & 1.848 & 1.257 & 0.211 & 0.0 & 2246. \\
\hline$Z$ & 1.831 & 1.246 & 0.210 & 0.0 & 2227. \\
\hline \multicolumn{6}{|c|}{$\begin{array}{l}\text { triangular section: } \\
s=2.02\end{array}$} \\
\hline$E_{\mathrm{f}}$ & 0.0018 & 0.0005 & 0.00018 & 0.00010 & 0.00008 \\
\hline$H$ & 1.464 & 1.139 & 0.631 & 0.125 & $4.75 \times 10^{-4}$ \\
\hline$Z$ & 1.451 & 1.129 & 0.625 & 0.124 & $4.70 \times 10^{-4}$ \\
\hline
\end{tabular}

\section{Teton Dam}

The Teton Dam, located on the Teton River, Idaho, failed on June 5, 1976. According to Ray et al. [4], of the approximately $310,300,000 \mathrm{~m}^{3}$ of water contained in the reservoir, $70 \%$ drained through the breached section within 3 hours. The estimated peak discharge was $65,000 \mathrm{~m}^{3} / \mathrm{s}$. The failure started as a leak that developed on the downstream face of the dam. Water discharge increased as the piping process continued until eventually the crest of the embankment collapsed into the water. Within the following ten minutes, the erosion process reached the bottom elevation of the dam.

For application of the dimensionless analytical solutions, the following input parameters are assumed: $H_{0}=1615.96 \mathrm{~m}, Z_{0}=1614.96 \mathrm{~m}, H_{\mathrm{b}}=1538 \mathrm{~m}, A_{\mathrm{s}}=8,029,162 \mathrm{~m}^{2}, C_{\mathrm{u}}=1.5 \sqrt{\mathrm{m}} / \mathrm{s}, b=65$ $\mathrm{m}$, and $s=0.8$. These input parameters and the corresponding dimensionless parameters are tabulated in Table 2.

\section{Analysis of results}

Table 3 summarizes results of application of the dimensionless solutions to the South Fork Dam for different values of $n$. A better description of the erosion process, however, is shown in Figs. 2 
Table 2. Input data and dimensionless parameters for application of the analytical solutions to the Teton Dam

\begin{tabular}{|c|c|c|c|c|c|}
\hline \multirow[b]{2}{*}{ variable } & \multicolumn{5}{|c|}{ exponent $n$} \\
\hline & 0 & 1 & 2 & 3 & 4 \\
\hline \multicolumn{6}{|c|}{$\begin{array}{l}H_{0}=1615.96 \mathrm{~m} \\
Z_{0}=1614.96 \mathrm{~m} \\
H_{\mathrm{b}}=1538.00 \mathrm{~m} \\
A_{\mathrm{s}}=8,029,162 \mathrm{~m}^{2} \\
C_{\mathrm{u}}=1.5 \sqrt{\mathrm{m} / \mathrm{s}}\end{array}$} \\
\hline \multicolumn{6}{|c|}{$\begin{array}{l}\text { rectangular section: } \\
b=65.0 \mathrm{~m}\end{array}$} \\
\hline$E_{\mathrm{f}}$ & 0.018 & 0.0025 & 0.00045 & 0.00012 & 0.00004 \\
\hline$H$ & 0.600 & 0.252 & 0.0112 & 0.0 & 21679. \\
\hline$Z$ & 0.592 & 0.249 & 0.0110 & 0.0 & 21401. \\
\hline \multicolumn{6}{|c|}{$\begin{array}{l}\text { triangular section: } \\
s=0.8\end{array}$} \\
\hline$E_{\mathrm{f}}$ & 0.016 & 0.0022 & 0.00042 & 0.00012 & 0.00004 \\
\hline$H$ & 0.759 & 0.525 & 0.228 & $2.88 \times 10^{-2}$ & $4.25 \times 10^{-5}$ \\
\hline Z & 1.451 & 1.129 & 0.625 & $2.84 \times 10^{-2}$ & $4.19 \times 10^{-5}$ \\
\hline
\end{tabular}

to 4 . Fig. 2 shows the influence of $n$ on the relation between $h^{\prime}$ and $z^{\prime}$. Fig. 3 shows how $z^{\prime}$ evolves with time as $n$ varies from 0.0 to 4.0 . Fig. 4 shows the corresponding breach hydrographs.

Likewise, Table 4 summarizes results from application of the dimensionless solutions to the Teton Dam for different values of $n$. Fig. 5 shows the influence of $n$ on the relation between $h^{\prime}$ and $z^{\prime}$. Fig. 6 shows the influence of $n$ on the relation between $z^{\prime}$ and $t^{\prime}$. Fig. 7 shows the corresponding breach hydrographs.

Table 3. Results of application of the dimensionless analytical solutions to the South Fork Dam

\begin{tabular}{|c|c|c|c|c|c|c|}
\hline \multirow{2}{*}{$\begin{array}{l}\text { output } \\
\text { variable }\end{array}$} & \multicolumn{5}{|l|}{ exponent $n$} & \multirow{2}{*}{$\begin{array}{l}\text { from the } \\
\text { BEED } \\
\text { model }\end{array}$} \\
\hline & 0 & 1 & 2 & 3 & 4 & \\
\hline rectangular section: & $1.61 \times 10^{-2}$ & $1.09 \times 10^{-2}$ & $1.84 \times 10^{-3}$ & 0.0 & 19.5 & \\
\hline$T$ & 1.831 & 2.27 & 5.26 & $\infty$ & $5.18 \times 10^{-2}$ & \\
\hline$T_{\mathrm{f}} \quad(\mathrm{h})$ & 3.5 & 3.6 & 3.4 & 3.5 & 3.5 & 3.37 \\
\hline$Q_{\mathrm{p}} \quad\left(\mathrm{m}^{3} / \mathrm{s}\right)$ (computed $)$ & 2,584 & 3,188 & 4,615 . & 6,165 & 7,116 & 6,087 \\
\hline$Q_{p} \quad\left(\mathrm{~m}^{3} / \mathrm{s}\right)$ (observed) & 7,050 & 7,050 & 7,050 & 7.050 & 7,050 & 7,050 \\
\hline$\Delta Q_{p}(\%)$ & -63.3 & -54.8 & -34.5 & -12.6 & 0.9 & -13.6 \\
\hline \multicolumn{7}{|l|}{ triangular section: } \\
\hline$T$ & 1.45 & 2.02 & 4.87 & 55.2 & $2.40 \times 10^{5}$ & \\
\hline$T_{\mathrm{f}} \quad(\mathrm{h})$ & 3.5 & 3.4 & 3.3 & 3.4 & 3.4 & 3.37 \\
\hline$Q_{\mathrm{p}} \quad\left(\mathrm{m}^{3} / \mathrm{s}\right)($ computed $)$ & 2,459 & 3,313 & 4,848 & 6,631 & 7,543 & 6,087 \\
\hline$Q_{\mathrm{p}} \quad\left(\mathrm{m}^{3} / \mathrm{s}\right)$ (observed) & 7,050 & 7,050 & 7,050 & 7.050 & 7,050 & 7,050 \\
\hline$\Delta Q_{\mathrm{p}}(\%)$ & -65.1 & -53.0 & -31.2 & -5.9 & 7.0 & -13.6 \\
\hline
\end{tabular}

According to Tables 3 and 4 , as $n$ decreases, so does $Q_{\mathrm{p}}$. Explanation for this phenomenon lies in the influence of $n$ on erosion rate. As $n$ decreases, rate of erosion becomes more linear with respect to time, allowing, therefore, more water discharge to occur during the breach evolution. 
On the other hand, as $n$ increases, rate of erosion is slow at the beginning stages of the process, but accelerates as time progresses. The result is a sharper breach hydrograph, with less reservoir depletion during the breach evolution. Therefore, $Q_{\mathrm{p}}$ is higher. Also, as $n$ increases, $Q_{\mathrm{p}}$ tends to approach observed values and the results given by the BEED model.

Table 4. Results of application of the dimensionless analytical solutions to the Teton Dam

\begin{tabular}{|c|c|c|c|c|c|c|}
\hline \multirow{2}{*}{$\begin{array}{l}\text { output } \\
\text { variable }\end{array}$} & \multicolumn{5}{|l|}{ exponent $n$} & \multirow{2}{*}{$\begin{array}{l}\text { from the } \\
\text { BEED } \\
\text { model }\end{array}$} \\
\hline & 0 & 1 & 2 & 3 & 4 & \\
\hline $\begin{array}{l}\text { rectangular section: } \\
(H-Z)\end{array}$ & rectangular section: & $3.24 \times 10^{-3}$ & $1.44 \times 10^{-4}$ & 0.0 & 278 & \\
\hline$T$ & 0.59 & 0.91 & 4.48 & $\infty$ & $3.60 \times 10^{-3}$ & \\
\hline$T_{\mathrm{f}} \quad(\mathrm{h})$ & 1.2 & 1.2 & 1.2 & 1.2 & 1.4 & 1.35 \\
\hline$Q_{\mathrm{F}} \quad\left(\mathrm{m}^{3} / \mathrm{s}\right)$ (computed $)$ & 51,862 . & 55,760 & 60,323 & 64,592 & 66,570 & 68,581 \\
\hline$Q_{\mathrm{p}} \quad\left(\mathrm{m}^{3} / \mathrm{s}\right)$ (observed) & 65,000 & 65,000 & 65,000 & 65.000 & 65,000 & 65,000 \\
\hline$\Delta Q_{p}(\%)$ & -20.2 & -14.2 & -7.2 & -0.6 & 2.4 & 5.5 \\
\hline \multicolumn{7}{|l|}{ triangular section: } \\
\hline$T$ & 0.75 & 1.30 & 4.37 & 92.1 & $1.81 \times 10^{6}$ & \\
\hline$T_{\mathrm{f}} \quad(\mathrm{h})$ & 1.3 & 1.3 & 1.3 & 1.2 & 1.3 & 1.35 \\
\hline$Q_{p}\left(\mathrm{~m}^{3} / \mathrm{s}\right)$ (computed) & 46,995 & 52,018 & 58,007 & 62,878 & 64,386 & 68,581 \\
\hline$Q_{p} \quad\left(\mathrm{~m}^{3} / \mathrm{s}\right)$ (observed) & 65,000 & 65,000 & 65,000 & 65.000 & 65,000 & 65,000 \\
\hline$\Delta Q_{p}(\%)$ & -27.7 & -20.0 & -10.8 & -3.3 & -0.9 & 5.5 \\
\hline
\end{tabular}

Normally, $A_{\mathrm{s}}$ is expected to vary substantially with depth. Since $A_{\mathrm{s}}$ was assumed to remain constant throughout the derivation of the dimensionless solutions, better results should be expected for larger reservoirs, where significant depletion usually does not occur during the breach evolution. In fact, as can be seen from Figs. 2 and 5, regardless of $n$, values of $h^{\prime \prime}$ obtained from the BEED model are much closer to those derived with dimensionless analytical solutions for the Teton Dam than those for the South Fork Dam.

According to Figs. 3 and 6, the choice between rectangular section and triangular section does not seem to have any significant influence as far as rate of erosion is concerned. In both cases, for equal values of $n$, the corresponding curves $z^{\prime}$ vs $t^{\prime}$ tend to coincide. However, the use of triangular section seems to provide better results with regard to reservoir depletion during the breach evolution. In fact, regardless of $n$, values of $h^{\prime \prime}$ for a triangular section are higher and tend to coincide better with the results derived from the BEED model than those for rectangular section.

As stated before, the dimensionless parameters $H, Z$ and $T$ are based on information that is given beforehand. A closer analysis reveals that each of these parameters contains all the physical and geometric information needed to define any particular case of dam failure. It may be possible, then, to attempt different types of correlation for several historical cases, based on $H, Z$ and $T$. In this study, a relation between $(H-Z)$ and $T$ is attempted, as shown below.

One of the most critical aspects of dam-breach erosion modeling is determining initial breach size. According to equations (27), (32), (47) and (52), breach formation time, which is represented by the parametric factor $T$, depends entirely on $(H-Z)$, which accounts for initial breach depth. Based on information provided in Tables 3 and 4 for rectangular sections, Fig. 8 was constructed. In general, larger values of $(H-Z)$ should mean smaller values of $T$. This tendency is observed, according to Fig. 8, for larger values of $n$, regardless of the type of section assumed. It may be noted that even though the Teton Dam failure and the South Fork Dam failure were very dif- 


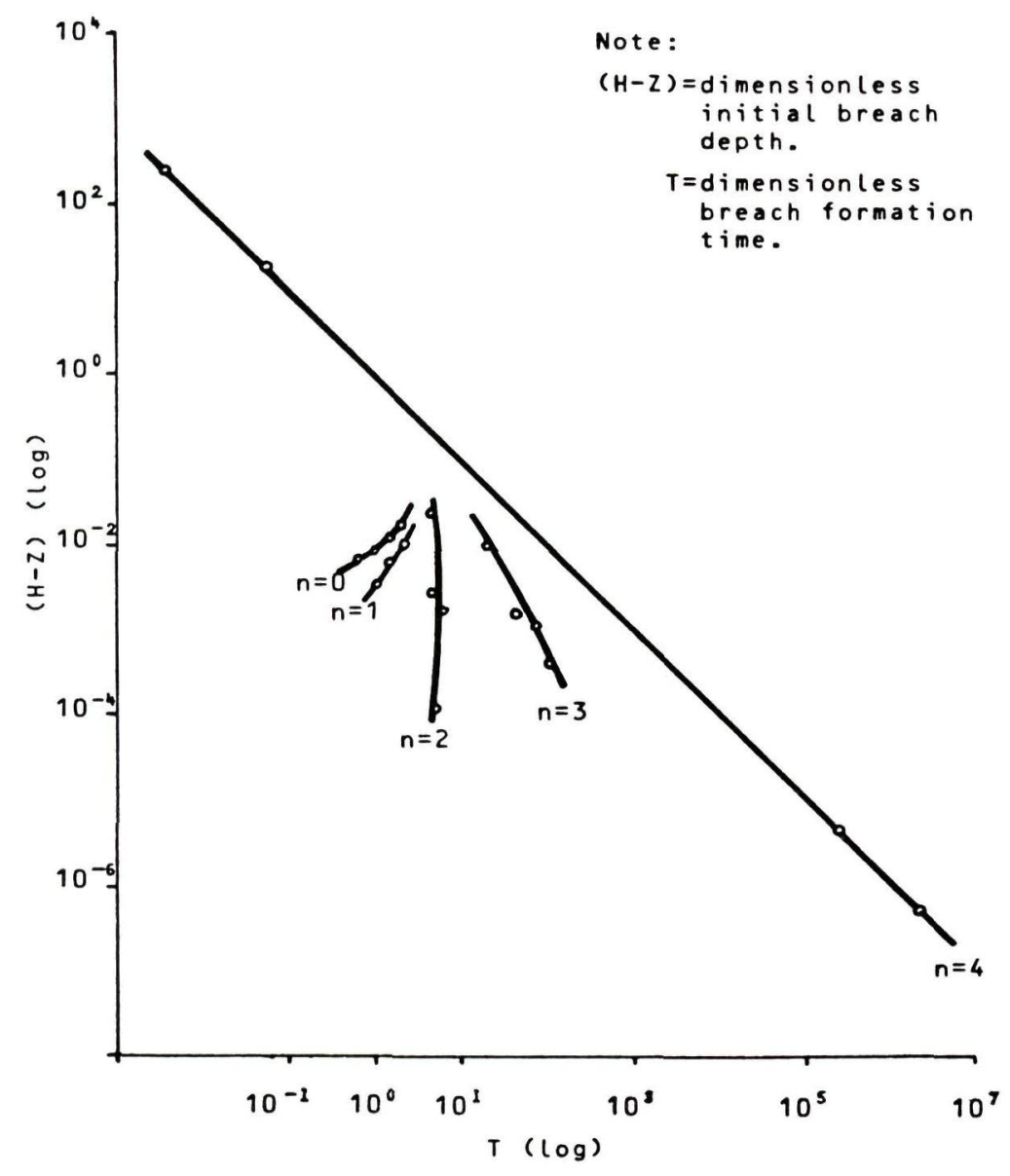

Fig. 8. Relation between $(H-Z)$ and $T$.

Relation entre $(H-Z)$ et $T$.

ferent in physical characteristics and time of evolution, Fig. 8 seems to provide a link between them.

\section{Sensitivity analysis}

Applicability of the analytical solutions for dam-breach erosion derived in this study depends on reliable estimation of $E_{\mathrm{f}}$ and $n$. It has already been shown that that higher values of $n$ provide more realistic estimates of $Q_{\mathrm{p}}$. Therefore, the sensitivity analysis that follows is limited to evaluating the influence of $E_{\mathrm{f}}$ on $Q_{\mathrm{p}}$ and $T_{\mathrm{f}}$. Throughout the analysis, $n$ is assumed to be equal to 4 , and the breach section to be triangular.

Fig. 9 illustrates the influence of $E_{\mathrm{f}}$ on $Q_{\mathrm{p}}$ and $T_{\mathrm{f}} . Q_{\mathrm{p}}$ is almost independent of changes in $E_{\mathrm{f}}$. Changes of even $100 \%$ in $E_{\mathrm{f}}$ produce variations of less than $3 \%$ in $Q_{\mathrm{p}}$. As stated before, as $n$ increases, most of the breach erosion process tends to take place in the last moments of the breach formation time, preventing a significant reservoir depletion during the process. Therefore, the corresponding value of $Q_{\mathrm{p}}$ tends to remain constant regardless of $E_{\mathrm{f}}$. 


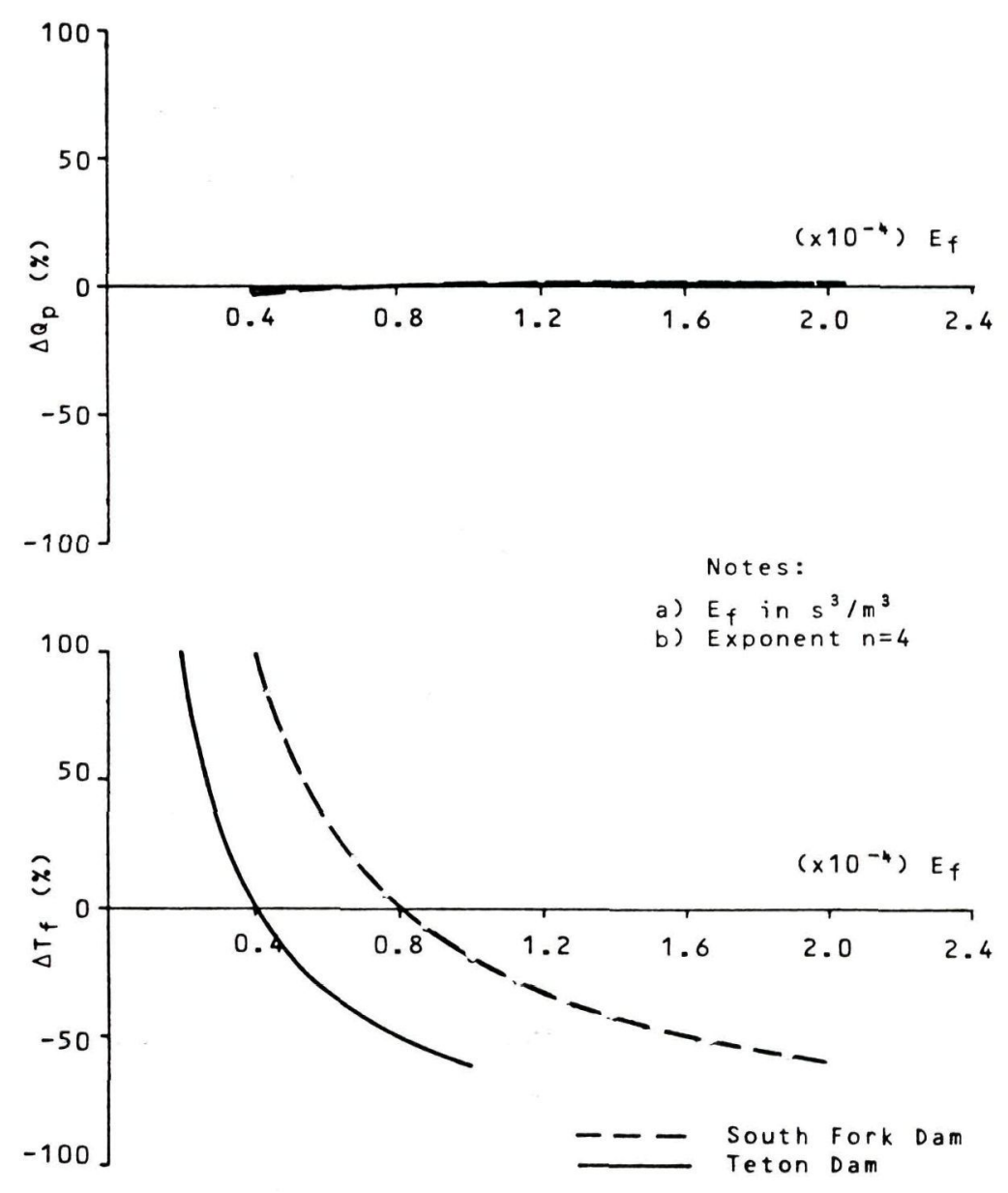

Fig. 9. Sensitivity of water peak discharge $\left(Q_{\mathrm{p}}\right)$ and breach formation time $\left(T_{\mathrm{f}}\right)$ to changes in the erodibility factor $\left(E_{\mathrm{f}}\right)$.

Influence du facteur d'érosion $E_{\mathrm{f}}$ sur le temps $\left(T_{\mathrm{f}}\right)$ de formation de la brèche et sur le débit de pointe $\left(Q_{\mathrm{p}}\right)$.

As opposed to $Q_{\mathrm{p}}, T_{\mathrm{f}}$ is significantly sensitive to changes in $E_{\mathrm{f}}$. Errors of $50 \%$ in $E_{\mathrm{f}}$ may lead to variations close to $100 \%$ in $T_{\mathrm{f}}$. This result indicates the need for means to determine accurate values of $E_{\mathrm{f}}$ so that reliable breach formation time estimates can be obtained.

\section{Conclusions}

The closed form dimensionless analytical solutions for higher values of $n$ were found to properly simulate dam breach erosion.

Estimates of breach formation time, based on the dimensionless solutions, were found to be highly dependent on the empirical erodibility factor $E_{\mathrm{f}}$. However, peak discharge did not appear to be sensitive to $E_{\mathrm{f}}$. This tendency coincides with the influence that Chezy's friction factor has on the BEED model (Quiroga and Singh, 1987) [6], and indicates the need for means to accurately measure the effects of friction on rapidly changing flow. 
Triangular section was shown to provide a better simulation of breach evolution than rectangular section.

\section{Acknowledgements}

This study was supported in part by the U.S. Army Engineer Waterways Experiment Station, Environmental Laboratory, under the project, "Sensitivity Analysis of Dam Breach Erosion Parameters and its Impact on Sediment Routing".

\section{References / Bibliographie}

1. Francis, J. B. et al., Report of the Committee on the Cause of the Failure of the South Fork Dam. Transactions, ASCE, Vol. 24, N. 477, June 1981, pp. 431-469.

2. Lou, W. C., Mathematical Modeling of Earth Dam Breaches. Dissertation, Colorado State University, Fort Collins, Colorado, 1981.

3. Quiroga, C. A. and Singh, V. P., A Dam-Breach Erosion Model: II. Application. Water Resources Management, Vol. 1, pp. 199-221, 1987.

4. RAY, H. A. et al., The Flood in Southeastern Idaho from the Teton Dam Failure of June 5, 1976. U.S. Geological Survey Open-File Report 77-765, 1978.

5. Simons, D. B. and Senturk, F., Sediment Transport Technology. Water Resources Publications, Fort Collins, Colorado, 1977.

6. Singh, V. P. and Quiroga, C. A., A Dam-Breach Erosion Model: I. Formulation. Water Resources Management, Vol. 1, pp. 177-197, 1987.

7. Singh, V. P. and Scarlatos, P. D., Breach Erosion of Earthfill Dams and Flood Routing: BEED model. U.S. Army Engineer Waterways Experiment Station, Environmental Laboratory, Military Hydrology Report, 1985.

8. Spiegel, M. R., Mathematical Handbook of Formulas and Tables. McGraw-Hill Book Co., New York, 1968. 